\title{
Correlation between body mass index and overactive bladder symptoms in pre-menopausal women
}

\author{
Thais Palma ${ }^{1}$, Marina Raimondi $^{1}$, Sophia Souto ${ }^{1}$, Celina Fozzatti $^{1}$, Paulo Palma $^{1}$, Cassio Riccetto $^{1}$ \\ ${ }^{1}$ UNICAMP - State University of Campinas, Campinas, SP, Brazil
}

\section{SUMmARY}

Objective: The aim of the study was to establish a correlation between Overactive Bladder (OAB) symptoms and Body Mass Index (BMI) in women aged 20-45. Methods: We interviewed 1.050 women aged 20-45 in the area of Campinas, Brazil, to investigate the prevalence of overactive bladder symptoms. In this study, we used the ICIQ-OAB questionnaire (ICS standard), in its validated portuguese version and a specific questionnaire for the demographics, which includes information about BMI.

Results: Overall, women with BMI $\geq 30$ presented a significantly higher score than women with a lower BMI (18.5 - 24.9) ( $\mathrm{p}=0.0066)$. In the analysis of individual symptoms, no significant differences were found regarding urinary frequency $(\mathrm{p}=0.5469)$. Women with BMI $\geq 30$ presented more nocturia than women with BMI ranging between 18.5 and $24.9(\mathrm{p}=0.0154)$. Women in the group of BMI 25 - 29.9 presented more urgency than women with BMI 18.5 - 24.9 ( $\mathrm{p}=0.0278)$. Significant difference was also found regarding urge-incontinence; women with BMI $25-29.9$ presented a higher score than women in the group $18.5-24.9(\mathrm{p}=$ 0.0017). Analysis was also performed on the visual analogue scale regarding how much each symptom bothers the women (quality of life). There were no significant differences regarding frequency, nocturia or urgency but urgency incontinence bother was significant. Women with BMI $25-29.9$ were more bothered by incontinence than women with BMI 18.5 - $24.9(\mathrm{p}=0.002)$.

Conclusion: In conclusion, this study reinforces the correlation between BMI and $\mathrm{OAB}$ symptoms. Obese women present more $\mathrm{OAB}$ symptoms than non-obese women.

Key words: overactive bladder, ICIQ-OAB questionnaire, body mass index.

\section{INTRODUCTION}

Overactive Bladder Syndrome (OAB) is a condition that causes great discomfort. It's more prevalent in post-menopausal women, in which its impact in quality of life is well known. ${ }^{1}$ However, the prevalence of $\mathrm{OAB}$ in premenopausal women is not well established, since urinary stress incontinence appears to be more frequent in that subset of patients. OAB is defined by the International Continence Society (ICS) as urinary urgency, with or without urgency incontinence and frequently associated with increase of frequency and noctúria. ${ }^{2}$

It has been suggested that $\mathrm{OAB}$ incidence is not related to age, $;, 4$ many women who are young and active have their lives limited due to discomfort caused by OAB.
Their complaints include embarrassment, emotional distress, chronic fatigue caused by nocturia, increase of risk of urinary tract infections due to chronic vaginal flora changes, decrease of both mobility and social interactions and depression. ${ }^{1,4,5}$ Women also reported coping strategies to avoid the desire to void, such as reducing the amount of liquids ingested, urinating before leaving the house and sleeping, finding and staying close to public restrooms when away from home. ${ }^{4}$

The high prevalence of $\mathrm{OAB}$ and its impact in quality of life justify the proposal of further related studies, so that new policies can be developed regarding information, treatment and improvement of quality of life in peo- 
ple affected by the condition. Strong associations between obesity and overactive bladder have been reported, ${ }^{6-10}$ which led to the development of a deeper analysis regarding each individual symptom in our study.

\section{Objective}

The aim of the study was to establish a correlation between OAB symptoms and Body Mass Index in women aged 2045 in Campinas, São Paulo, Brazil.

\section{Methods}

This is an epidemiological study, in which we interviewed women aged 20 to 45 years, in the region of Campinas, to ascertain the prevalence of symptoms of Overactive Bladder. For inclusion in the study, subjects must have regular menstrual cycles, without any complaint that would suggest premature menopause.

The project was approved by the Ethics Committee in Research at Medical School of State University of Campinas, Protocol \# 1092/2008.

Prior to inclusion in the trial, subjects were informed of the nature of the study and were given information relevant to the intended purpose. A document of informed consent, approved by the ethics committee, was signed by the subject, by the investigator and, if necessary, by a witness.

The study excluded women with diabetes mellitus, chronic lung disease, history of recurrent urinary tract infections, neurological diseases and other conditions that can predispose to neurogenic detrusor overactivity. Patients who underwent surgery for urinary incontinence and other major pelvic surgery were also excluded.

For the study we used a specific questionnaire containing information about gender, age, weight, height, education, profession, obstetric history, urinary tract infections, urinary incontinence and other pelvic surgeries, diabetes, chronic pulmonary disease and neurological conditions. The women who were included in the study completed the International Consultation on Incontinence Questionnaire - Overactive Bladder (ICIQ-OAB) ${ }^{11}$ standardized by the International Society for Incontinence (ICS), translated and validated into portuguese, ${ }^{12}$ designed to obtain data about overactive bladder. This questionnaire was considered highly responsive in the quantification of urgency, frequency and incontinence in $\mathrm{OAB}$ patients. ${ }^{13}$ The International Consultation on Incontinence Questionnaire - Overactive Bladder (ICIQ-OAB) is a simple, fast and self-administrable questionnaire. It consists of 6 questions, num- bers 1 and 2 being date of birth and gender. Questions 3, 4, 5 and 6 are divided in A and B. Question 3A determines frequency, and $3 \mathrm{~B}$ is a Visual Analogue Scale (VAS) about the symptom bother (from 1 to 10). Question 4A determines nocturia and $4 \mathrm{~B}$ the VAS quantification. Question 5A determines urgency and question 6A determines urgency incontinence, all followed by the question B, symptom bother. All the B questions are not included in the score, but help us understand how much that specific symptom bothers the patient, quantifying quality of life (QoL).

The determination of sample size was conducted with the assistance of the Department of Statistics, Faculty of Medical Sciences of the State University of Campinas. The collected data were entered into Excel (Microsoft ${ }^{\circledR}$ Corporation, Redmond, WA, USA). Descriptive analysis of presentation of tables for categorical variables was performed, with frequencies and measures of dispersion and position for numeric variables. For comparison of proportions the Chi-square test was used. For comparison of numeric measurements between 2 groups the MannWhitney test was used and among 3 or more groups, the Kruskal-Wallis test or ANOVA with processing by posts followed by Tukey test for location of differences, when necessary. In order to verify linear association between 2 bullets the Spearman correlation coefficient was used. This coefficient varies from -1 to 1 . Values close to the extremes indicate positive or negative correlation, respectively, and values close to 0 indicate no correlation. The significance level used for statistical testing was 5 ( $\mathrm{p} \leq 0.05$ ). SAS System for Windows (Statistical Analysis System), version 9.2. SAS Institute Inc, 2002-2008, Cary, NC, USA was used for statistical analysis.

\section{Results}

A total of 1.050 women were included in the study. The age of the women ranged between 20 and 45 years old, and the average age was 28.6 years. The average BMI was 22.8 , varying between 14.8 and 42.5 . BMI was calculated dividing the weight in kilograms by height in meters squared (weight $(\mathrm{kg}) /[\text { height }(\mathrm{m})]^{2}$ ).

The individual scores for each question and the total score are listed in table 1 .

In the analysis of the score of questionnaire ICIQ$\mathrm{OAB}$ related to $\mathrm{BMI}$ (figure 1), regarding urinary frequency (question 3A), the average score was 0.5 points for women with BMI < 18.5, for women between 18.5 and 24.9, and also in the group of 25 and 29.9, and for the obese group (BMI $\geq 30$ ) the average score was 0.6. No significant differences were found $(\mathrm{p}=0.5469)$. 
TABLE 1 Body mass index vs. symptoms (ICIQ-OAB)

\begin{tabular}{l|l|l|l|l|l} 
BMI & $\begin{array}{l}\text { Frequency } \\
(3 \mathrm{~A})\end{array}$ & $\begin{array}{l}\text { Nocturia } \\
(4 \mathrm{~A})\end{array}$ & $\begin{array}{l}\text { Urgency } \\
(5 \mathrm{~A})\end{array}$ & $\begin{array}{l}\text { Urgency } \\
\text { Incontinence } \\
(6 \mathrm{~A})\end{array}$ & Score \\
\hline$<18.5$ & 0.5 & 0.5 & 0.7 & 0.3 & 2.1 \\
\hline $18.5-24.9$ & 0.5 & 0.5 & 0.9 & 0.3 & 2.2 \\
\hline $25-29.9$ & 0.5 & 0.6 & 1.1 & 0.5 & 2.7 \\
\hline$\geq 30$ & 0.6 & 0.9 & 1.2 & 0.4 & 3.1 \\
\hline p value & 0.5469 & 0.0154 & 0.0278 & 0.0017 & 0.0066 \\
\hline & & & & &
\end{tabular}

Regarding nocturia (question 4A), the average score was 0.4 for women with $\mathrm{BMI}<18.5$. In the group with BMI ranging from 18.5 to 24.9 , the average score was 0.5 . A score of 0.6 was found for women between 25 and 29.9. Women with BMI $\geq 30$ presented a score of 0.9 , meaning more symptoms than women with BMI ranging between 18.5 and $24.9(\mathrm{p}=0.0154)$.

In the analysis of urgency (question 5A), women with BMI $<18.5$ presented a score of 0.7 , while the ones with BMI between 18.5 and 24.9 had an average of 0.9 . The group between 25 and 29.9 had a score of 0.5 , and the obese women presented a score of 1.2. The women in the group of BMI 25 - 29.9 presented more symptoms than women in the first group (18.5 - 24.9) ( $\mathrm{p}=0.0278)$.

In the last parameter, urgency incontinence (6A), the score was 0.3 for women with BMI $<18.5$, and with BMI between 18.5 and 24.9. The group ranging between BMI 25 - 29.9 had a score of 0.5 , and in the group with BMI $\geq 30$ the score was 0.4 . Significant difference was found between women with BMI 25 - 29.9 and women in the group $18.5-24.9(\mathrm{p}=0.0017)$.
Overall, women with BMI $\geq 30$ presented a significantly higher score than women with a lower BMI (18.5 - 24.9). $(\mathrm{p}=0.0066)$ (figure 2).

Analysis was also performed regarding the part B, where patients report how much each symptom bothers them (figure 3).

Regarding urinary frequency (question 3B), the average score was 1.3 for women with $\mathrm{BMI}<18.5$. The average score for women with BMI between 18.5 and 24.9 was 1.0. In the group of women with BMI between 25 and 29.9, the average score was 1.1, and for the obese group (BMI $\geq 30$ ) the average score was 1.5 . No significant differences were found $(\mathrm{p}=0.165)$.

Regarding nocturia (question $4 \mathrm{~B}$ ), the average score was 1.4 for women with BMI <18.5. In the group with BMI ranging from 18.5 to 24.9 , the average score was 1.2. A score of 1.1 was found for women between 25 and 29.9. Women with BMI $\geq 30$ presented a score of 1.5 . No significant differences were found ( $p=0.427)$.

In the analysis of urgency (question 5B), women with BMI < 18.5 presented a score of 1.3 , while the ones with BMI between 18.5 and 24.9 had an average of 1.1. The group between 25 and 29.9 had a score of 1.6 , and the obese women presented a score of 1.7. No significant differences were found ( $p=0.2583$ ).

In the last parameter, urgency incontinence $(6 \mathrm{~B})$, the score was 1.0 for women with BMI $<18.5$, and 0.9 for those with BMI between 18.5 and 24.9. The group ranging between BMI 25 - 29.9 had a score of 1.6, and in the group with $\mathrm{BMI} \geq 30$ the score was 1.4. Significant difference was found between women with BMI 18.5 - 24.99 and women in the group $25-29.9(\mathrm{p}=0.002)$.

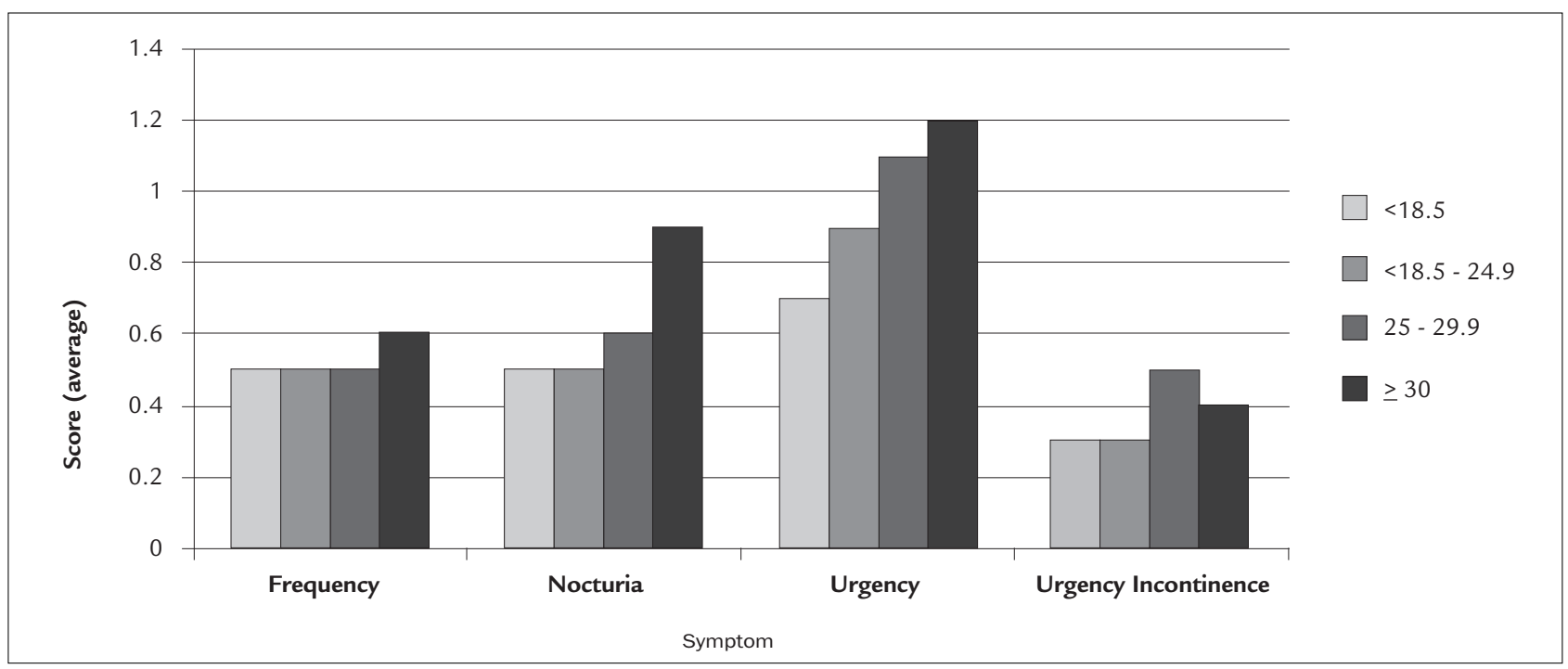

FIGURE 1 Score of each symptom in each body mass index group - ICIQ-OAB questionnaire 


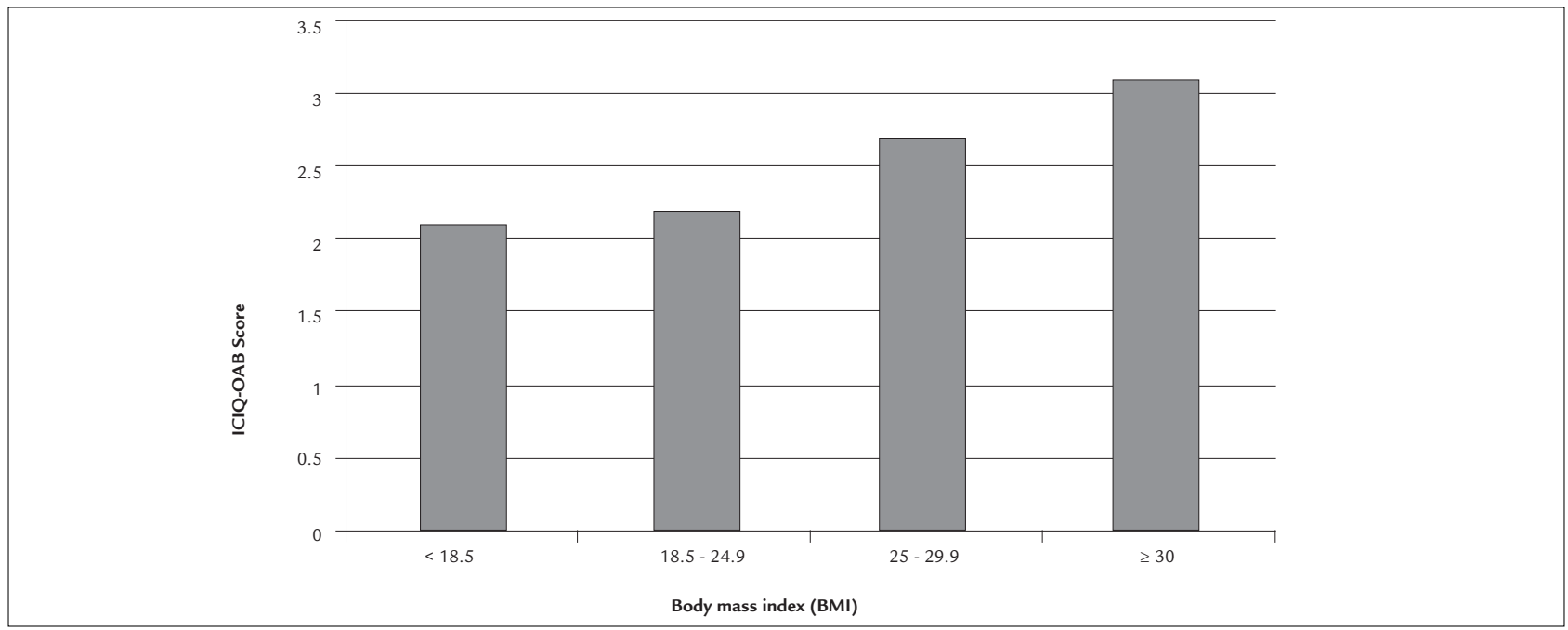

FIGURE 2 ICIQ-OAB questionnaire score vs. body mass index

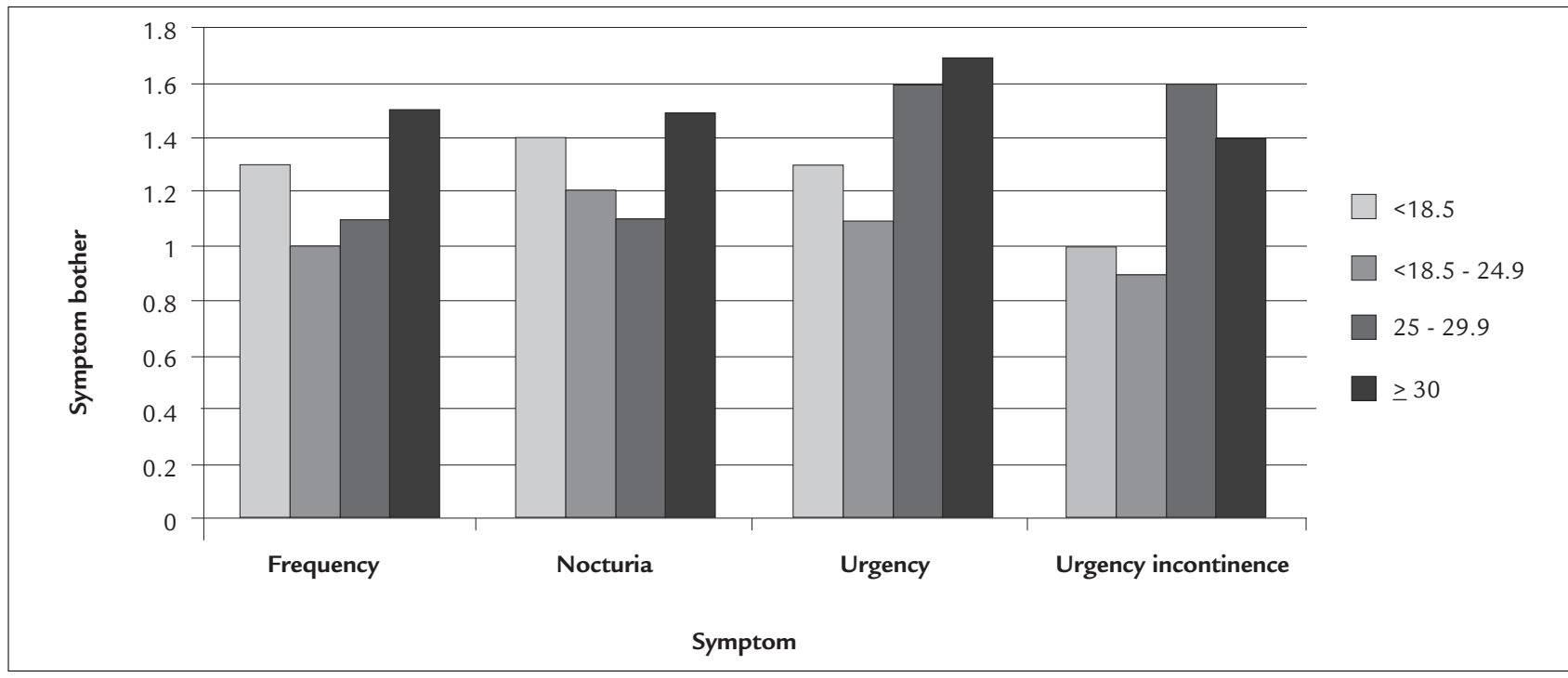

FIGURE 3 Symptom bother in each body mass index group - ICIQ-OAB questionnaire

There were no significant differences regarding frequency, nocturia or urgency. The difference in urgency incontinence bother was significant between the third and second groups (25 - $29.9>18.5$ - 24.9) $(\mathrm{p}=0.002)($ table 2$)$.

\section{TABLE 2 Body mass index vs. symptom bother (ICIQ-OAB)}

\begin{tabular}{l|l|l|l|l} 
BMI & $\begin{array}{l}\text { Frequency } \\
(3 \mathrm{~B})\end{array}$ & $\begin{array}{l}\text { Nocturia } \\
(4 \mathrm{~B})\end{array}$ & $\begin{array}{l}\text { Urgency } \\
(5 \mathrm{~B})\end{array}$ & $\begin{array}{l}\text { Urgency } \\
\text { incontinence (6B) }\end{array}$ \\
\hline$<18.5$ & 1.3 & 1.4 & 1.3 & 1 \\
\hline $18.5-24.9$ & 1 & 1.2 & 1.1 & 0.9 \\
\hline $25-29.9$ & 1.1 & 1.1 & 1.6 & 1.6 \\
\hline$\geq 30$ & 1.5 & 1.5 & 1.7 & 1.4 \\
\hline $\mathrm{P}$ value & 0.165 & 0.427 & 0.2583 & 0.002 \\
\hline
\end{tabular}

\section{Discussion}

Overactive bladder is a condition that can be observed in women of all ages, although it is known to increase with age. ${ }^{14}$ It is known to cause great discomfort, affecting the lives of many women, but it also affects men. ${ }^{2}$

Strong associations between obesity and both urinary and fecal incontinence have been reported. ${ }^{15,16} \mathrm{Ac}$ cording to the Clinical Guidelines on the Identification, Evaluation and Treatment of Overweight and Obesity in Adults, from the National Institutes of Health, (National Heart, Lung and Blood Institute), about 97 million adults are overweight or obese in the United States. The definition of overweight applies to an individual with BMI ranging from 25 to $29.9\left(\mathrm{~kg} / \mathrm{m}^{2}\right)$, and obese is an in- 
dividual with BMI over 30 . Obesity is a multifactorial chronic condition that results from interaction of genotype and environment. ${ }^{17}$

The prevalence of overweight in children and adolescents and obesity in adults in the United States has increased over several decades. Using data from the National Health and Nutrition Examination Survey (NHANES) of 4.149 women, prevalence estimates of overweight and obesity were calculated. In 2003-2004, 28.6\% of women were overweight and $33.2 \%$ were obese in the United States. ${ }^{18}$ In our study, $3.4 \%$ of the women were obese and $17.9 \%$ were overweight. ${ }^{17}$

In 1988, a study was performed searching for a correlation between urinary incontinence and obesity. Women were mailed a survey asking about incontinence episodes in 1987: whether the urinary incontinence episodes were generally provoked by physical stress, e.g., lifting, coughing, sneezing, or laughing (stress Urinary Incontinence - UI), and/or were accompanied by a feeling of urge to void (urgency urinary incontinence). In addition, they were queried as to their body height (centimeters) and weight (kilograms), their age, whether they had had their last menses, whether they had had children, whether they had undergone abdominal and gynecologic surgery, their experience with cystitis, and their occupation. The authors concluded that urinary incontinence seems to be associated with increased BMI. ${ }^{9}$

A retrospective study was performed with 136 patients presenting for urodynamic evaluation. The results demonstrate strong correlation between BMI and intra-abdominal pressure $(\mathrm{p}=0.0001)$. There was also a strong correlation between intra-abdominal pressure and BMI $(\mathrm{p}=0.0001)$. The relationship between intravesical pressure and $\mathrm{BMI}$ also demonstrated a high correlation. The study suggests that obesity might contribute to urinary incontinence due to increase of intra-abdominal pressure. The authors state that more studies need to be performed to objectively quantify the actual stress created by the increased abdominal pressure on the pelvic floor. ${ }^{19}$

In 2007, a study was conducted with 3.962 women in California, by mailing them a survey: the Epidemiology of Prolapse and Incontinence Questionnaire (EPIQ). Obese women were over twice as likely to experience SUI and OAB and $92 \%$ more likely to have any pelvic floor dysfunction than women who were not obese. It was concluded in the survey that obese women were more likely to have pelvic floor dysfunctions compared to non-obese women. ${ }^{8}$

Obesity and $\mathrm{OAB}$ were also linked in a study correlating $\mathrm{OAB}$ and Metabolic Syndrome (MetS), well known to be associated with obesity. A group of 313 patients with $\mathrm{OAB}$ and another of 208 patients without $\mathrm{OAB}$ were included in the prospective study. All the patients were invited to complete a survey consisting of LUTS (Lower Urinary Tract Symptoms) and a self-administered questionnaire, including questions regarding $\mathrm{OAB}$ risk factors and medical history. The urinary symptoms included the sense of urgency, urge incontinence, daytime urinary frequency, and nocturia. The quality-of-life measures included the $\mathrm{OAB}$ validated 8-question screener and a score of $>8$ was required for a diagnosis of OAB. Metabolic syndrome was diagnosed in 201 (64\%) of the patients with $\mathrm{OAB}$ and 73 (35\%) of the patients without $\mathrm{OAB}(\mathrm{p}=0.002)$. The authors conclude that metabolic syndrome is highly correlated with OAB. ${ }^{10}$

The results of the present study are consistent with those in the literature. The findings in the present study reinforce the correlation between obesity and overactive bladder that was found by the aforementioned authors. The use of a specific instrument (ICIQ-OAB) allows us to standardize the data and thus, enhance its reliability. Uniform and reproducible evaluation of OAB symptoms and its impact in QoL represents one of the most important aspects in any study about the topic, because it might determine variability in the results. In the present study, we found that women with BMI $\geq 30$ presented a significantly higher score than women with a lower BMI, from 18.5 to 24.9 ( $\mathrm{p}=0.0066$ ), correlating $\mathrm{OAB}$ and obesity.

The physiopathology mechanisms are probably multifactorial, and possibly related to mechanical or neuroendocrine factors. ${ }^{6}$ The increase in intravesical pressure originated by obesity exerts increased force on the pelvic floor. As a result, it could augment bladder afferent firing; which would lead to urgency and frequency. Stress induced urine entering the urethra could also trigger detrusor overactivity, leading to urgency and frequency. ${ }^{7}$

Another study also supports the mechanical hypothesis, reinforcing the correlation between BMI and intra-abdominal pressure, suggesting that obesity may create an increased intra-abdominal pressure and thus expose the pelvic support structures and organs to a chronic state of stress and pelvic floor muscle fatigue secondary to that increased pressure. Possible nerve damage may be introduced to the pudendal nerve secondary to the chronic state of increased intra-abdominal pressure. This could place obese patients at higher risk for developing urinary incontinence or for failing standard anti-incontinence procedures. ${ }^{19}$ It has also been stated that the mechanism of the hypothesized causative process may be dependent on the balance between the amount of intrapelvic tissue and the flexibility of the abdominal wall and 
the perineum as indicated by a relatively rapid increase in stress urinary incontinence prevalence along with an increasing BMI in nulliparous women. ${ }^{9}$

Aside from mechanical factors, neuroendocrine processes may also be responsible for the correlation between adiposity and OAB. The leptin produced by adipose tissue can increase autonomic nervous activity, especially noradrenergic sympathetic nerves. ${ }^{20}$ Increased perivesical fat (known as lipomatosis when in its pathologic form) can cause inflammation within the bladder, which could lead to urinary frequency and urgency. ${ }^{21}$ That leads to the possibility of the visceral fat producing inflammatory cytokines, which could lead to urothelial irritation and therefore, the symptoms. ${ }^{6}$

Another association can be made between obesity and cardiovascular disease, which could result in vascular endothelial dysfunction. It has been demonstrated experimentally that increasing ischemia to the bladder can lead to overactivity in the detrusor. ${ }^{22}$

Regardless of the numerous hypotheses concerning the physiopathology mechanisms, the increase of obesity is a worldwide health problem that predisposes many conditions, such as diabetes, heart disease and also urinary problems, including overactive bladder. Women and health care professionals should be made aware of the association between urinary incontinence and obesity/overweight. They should encourage the women in this risk group to practice physical activities and adopt a healthy diet, in order to maintain a healthy weight. ${ }^{8}$ Although the incidence of $\mathrm{OAB}$ is lower in younger women, this group is specially affected by the symptoms, since they are more active and committed to labor activities, which causes a negative economic impact.

\section{Conclusion}

In conclusion, this study reinforces the correlation between $\mathrm{BMI}$ and $\mathrm{OAB}$ symptoms, regardless of age. Considering the current increase of obesity, health care professionals should be aware of the association between elevated BMI and $\mathrm{OAB}$ symptoms. Obese women should be advised to adopt a healthier lifestyle in order to prevent, among other known consequences, the symptoms of $\mathrm{OAB}$.

\section{AcKNOWLEDGEMENTS}

Project funded by CAPES grant process \# 6176/11-9.

No competing financial interests exist.

\section{Resumo}

Correlação entre índice de massa corporal e sintomas de bexiga hiperativa em mulheres no menacme
Objetivo: O objetivo do estudo foi estabelecer uma correlação entre os sintomas de bexiga hiperativa e índice de massa corporal (IMC) em mulheres com idades entre 20 e 45 anos.

Métodos: Foram entrevistadas 1.050 mulheres com idades entre 20 e 45 anos na região de Campinas, Brasil, para investigar a prevalência de sintomas de bexiga hiperativa. Neste estudo, foi utilizado o questionário ICIQ-OAB (padrão ICS), em sua versão validada em português e um questionário específico para os dados demográficos, que inclui informações sobre o IMC.

Resultados: As mulheres com IMC $\geq 30$ apresentaram uma pontuação significativamente maior do que as mulheres com IMC mais baixo (18,5 a 24,9); $\mathrm{p}=0,0066$. $\mathrm{Na}$ análise dos sintomas individuais, não foram encontradas diferenças significativas em relação a frequência urinária $(\mathrm{p}=0,5469)$. Mulheres com IMC $\geq 30$ apresentaram mais noctúria do que as mulheres com IMC variando entre 18,5 e 24,9 ( $p=0,0154)$. As mulheres no grupo de IMC 25 a 29,9 apresentaram mais urgência do que as mulheres com IMC 18,5 a 24,9 ( $p=0,0278)$. Também foi encontrada diferença significativa em relação à incontinência de urgência. As mulheres com IMC 25 a 29,9 apresentaram pontuação maior do que as mulheres no grupo 18,5 a 24,9 ( $\mathrm{p}=0,0017)$. A análise também foi realizada na escala analógica visual sobre quanto cada sintoma incomoda as mulheres (qualidade de vida). Não houve diferenças significativas em relação a frequência, noctúria e urgência, mas o incômodo causado pela incontinência de urgência foi significativo. Mulheres com IMC 25 a 29,9 foram mais incomodadas com a incontinência do que as mulheres com IMC 18,5 a 24,9 $(\mathrm{p}=0,002)$.

Conclusão: Em conclusão, este estudo reforça a correlação entre IMC e sintomas de bexiga hiperativa; mulheres obesas apresentam mais sintomas do que mulheres não obesas.

Unitermos: bexiga hiperativa, questionário ICIQ-OAB, índice de massa corporal.

\section{References}

1. Van der Vaart CH, de Leeuw JR, Roovers JP, Heintz AP. The effect of urinary incontinence and overactive bladder symptoms on quality of life in young women. BJU Int. 2002;90(6):544-9.

2. Abrams P. Describing bladder storage function: overactive bladder syndrome and detrusor overactivity. Urology. 2003;62(5 Suppl 2):28-37; discussion 40-2.

3. Dwyer PL, Rosamilia A. Evaluation and diagnosis of the overactive bladder Clin Obstet Gynecol. 2002;45(1):193-204.

4. Teloken C, Caraver F, Weber FA, Teloken PE, Moraes JF, Sogari PR, et al., Overactive bladder: prevalence and implications in Brazil. Eur Urol. 2006;49(6):1087-92. 
5. Christoph F, Moschkowitsch A, Kempkensteffen C, Schostak M, Miller K, Schrader M. Long-term efficacy of tolterodine and patient compliance in pediatric patients with neurogenic detrusor overactivity. Urol Int. 2007;79(1):55-9.

6. Link CL, Steers WD, Kusek JW, McKinlay JB. The association of adiposity and overactive bladder appears to differ by gender: results from the Boston Area Community Health survey. J Urol. 2011;185(3):955-63.

7. Dallosso HM, et al., The association of diet and other lifestyle factors with overactive bladder and stress incontinence: a longitudinal study in women. BJU Int. 2003;92(1):69-77.

8. Lawrence JM, Lukacz ES, Liu IL, Nager CW, Luber KM. Pelvic floor disorders, diabetes, and obesity in women: findings from the Kaiser Permanente Continence Associated Risk Epidemiology Study. Diabetes Care. 2007;30(10):2536-41.

9. Mommsen, S. and A. Foldspang, Body mass index and adult female urinary incontinence. World J Urol, 1994. 12(6): p. 319-22.

10. Uzun $\mathrm{H}$, Zorba OU. Metabolic syndrome in female patients with overactive bladder. Urology. 2012;79(1):72-5.

11. Abrams, P., et al., The International Consultation on Incontinence Modular Questionnaire: www.iciq.net. J Urol. 2006;175(3 Pt 1):1063-6; discussion 1066.

12. Pereira SB, Thiel Rdo R, Riccetto C, Silva JM, Pereira LC, Herrmann V, et al., [Validation of the International Consultation on Incontinence Questionnaire Overactive Bladder (ICIQ-OAB) for Portuguese]. Rev Bras Ginecol Obstet. 2010;32(6):273-8

13. Coyne KS, Matza LS, Thompson CL. The responsiveness of the Overactive Bladder Questionnaire (OAB-q). Qual Life Res. 2005;14(3):849-55.

14. Lee YS, Lee KS, Jung JH, Han DH, Oh SJ, Seo JT, et al. Prevalence of overactive bladder, urinary incontinence, and lower urinary tract symptoms: results of Korean EPIC study. World J Urol. 2011;29(2):185-90.

15. Richter HE, Burgio KL, Brubaker L, Moalli PA, Markland AD, Mallet V, et al. Factors associated with incontinence frequency in a surgical cohort of stress incontinent women. Am J Obstet Gynecol. 2005;193(6):2088-93.

16. Foldspang A, Mommsen A. [Overweight and urinary incontinence in women]. Ugeskr Laeger. 1995;157(42):5848-51.

17. Clinical Guidelines on the Identification, Evaluation, and Treatment of Overweight and Obesity in Adults--The Evidence Report. National Institutes of Health. Obes Res. 1998;6(Suppl 2):51S-209S.
18. Ogden CL, Carroll MD, Curtin LR, McDowell MA, Tabak CJ, Flegal KM. Prevalence of overweight and obesity in the United States, 1999-2004. JAMA. 2006;295(13):1549-55.

19. Noblett KL, Jensen JK, Ostergard DR. The relationship of body mass index to intra-abdominal pressure as measured by multichannel cystometry. Int Urogynecol J Pelvic Floor Dysfunct. 1997;8(6):323-6.

20. Shen J, Tanida M, Niijima A, Nagai K. In vivo effects of leptin on autonomic nerve activity and lipolysis in rats. Neurosci Lett. 2007;416(2):193-7.

21. Tong RS, Larner T, Finlay M, Agarwal D, Costello AJ. Pelvic lipomatosis associated with proliferative cystitis occurring in two brothers. Urology. 2002;59(4):602.

22. Azadzoi KM, Tarcan T, Kozlowski R, Krane RJ, Siroky MB. Overactivity and structural changes in the chronically ischemic bladder. J Urol. 1999;162(5):1768-78 .

\section{ERRATUM}

In the article "Correlation between body mass index and overactive bladder symptoms in pre-menopausal women", published in issue 2, volume 60, of the Journal of the Brazilian Medical Association, on page 111, where it reads:

"Marina Raimondi', Sophia Souto ${ }^{1}$, Celina Fozzatti1, Paulo Palma ${ }^{1}$, Cassio Riccetto ${ }^{1 "}$

\section{Read:}

"Thais Palma ${ }^{1}$, Marina Raimondi ${ }^{1}$, Sophia Souto ${ }^{1}$, Celina Fozzatti ${ }^{1}$, Paulo Palma ${ }^{1}$, Cassio Riccetto ${ }^{1 "}$ 